\title{
USULAN PERBAIKAN AREA KERJA MENGGUNAKAN METODE 5S GUNA TAHAP AWAL PENERAPAN LEAN MANUFACTURING (STUDI KASUS PT. XYZ)
}

\author{
Dika Priyanto $^{1 *}$ dan Indro Prakoso ${ }^{2}$ \\ ${ }^{1,2}$ Fakultas Teknik, Jurusan Teknik Industri, Universitas Jenderal Soedirman \\ Jl. Raya Mayjen Sungkono KM 5 , Dusun 2, Blater, Kalimanah, Purbalingga, Jawa Tengah 53371 \\ *email: dikaprynto@gmail.com
}

\begin{abstract}
PT. XYZ is a company engaged in wood processing. The product produced is plywood according to customer demand. After observing the production floor, several problems were found, namely that there was unused equipment in the work area. This equipment is equipment that is damaged or is not used. Besides, the cleanliness of the production floor is also poorly maintained where there is still dirt and dust. This study aims to identify problems related to waste on the production floor and design and propose the $5 S$ method to create an effective work environment. The method used in this study uses the 5S concept approach (Seiri, Seiton, Seiso, Seiketsu, Shitsuke). 5S assessment is carried out using the audit checklist and evaluation checklist. The audit checklist and evaluation checklist are filled out by an auditor who knows clearly how the actual conditions on the production floor are. Data were collected in five work areas, namely rotary, press dryer, repair, assembling, and packing. The results of this study can be concluded that 1) problems on the production floor of PT XYZ include: there is no written procedure for elimination, there is no label on the work area, there is no regular cleaning, employees do not understand $5 \mathrm{~s}$, there are no procedures and $5 \mathrm{~s}$ standards, there is no audit regarding $5 \mathrm{~s}$, there is no visual management system and standard procedures regarding $5 \mathrm{~s}$, lots of garbage scattered, dirty work surfaces and difficult to clean, everyone is not involved in 5 s activities; 2) The results of the $5 S$ assessment before improvement were $37.78 \%$ in the bad category. After planning the implementation of the improvement, the score rose to $80 \%$ in the good category.
\end{abstract}

Keywords: 5s Methods, Checklist Audit, Checklist Evaluasi

\section{Pendahuluan}

Perkembangan industri saat ini semakin pesat, khususnya pada sektor industri manufaktur. Menurut Silalahi, (2014) industri manufaktur mempunyai peran penting di dalam perekonomian Indonesia karena kemampuannya untuk menghasilkan produk yang dapat diperjual belikan dan dapat membuka lapangan kerja baru. Dalam dunia industri para pelaku bisnis harus memperhatikan kualitas produknya. Pada masa ini produk dituntut untuk memiliki kualitas yang tinggi serta harganya yang terjangkau. Seiring dengan adanya tuntutan tersebut dan berkembangnya teknologi maka dalam dunia industri berkembanglah suatu konsep lean manufacturing.

Lean manufacturing atau disebut juga dengan just in time manufacturing merupakan sebuah konsep yang dikembangkan oleh perusahaan toyota. Menurut Aisyah, (2020) konsep lean manufacturing bertujuan untuk mengubah suatu organisasi di perusahaan menjadi lebih efisien dan kompetitif. Aplikasi dari konsep lean manufacturing diantaranya yaitu untuk mengurangi lead time dan meningkatkan jumlah output dengan cara menghilangkan waste yang ada. Pada beberapa perusahaan di Indonesia masih belum menerapkan konsep lean manufacturing, ataupun sudah menerapkan namun belum dapat mengaplikasikannya secara optimal. Melihat keberhasilan toyota dalam menerapkan konsep lean manufacturing ini maka para pelaku bisnis di Indonesia perlu untuk menerapkan konsep lean manufacturing juga pada perusahaan mereka.

PT. XYZ merupakan perusahan pengolahan kayu yang berdiri sejak tahun 2014. Kegiatan usahanya yaitu mengolah kayu log yang diperoleh dari supplier menjadi kayu lapis untuk dijual ke pelanggan. Produk yang dihasilkan oleh PT. XYZ adalah plywood dengan ukuran bervariasi sesuai dengan permintaan konsumen. Saat ini pemasaran produk kayu lapis dari PT. XYZ tersebar di seluruh pulau jawa seperti Bandung dan Surabaya. Proses pengolahan kayu lapis secara garis besar meliputi spesifikasi dan pemotongan log kayu, pengupasan 
kayu menjadi lembaran tipis (rotary), pengeringan (pressdryer), penyambungan (repair), perakitan (assembling), seleksi (greading), dan pengepakan (packing).

Setelah melakukan pengamatan pada lantai produksi ditemukan beberapa masalah yaitu terdapat banyak alat yang tidak diperlukan berada di sekitar area kerja. Alat - alat tersebut merupakan alat yang sudah rusak atau sudah tidak digunakan. Selain itu, kebersihan di lantai produksi juga kurang terjaga dimana masih terdapat kotoran dan debu. Menurut Liker \& Hoseus (dalam Sylvia, 2020) area kerja yang tidak diatur dengan baik akan menimbulkan kebingungan, frustasi, dan penundaan. Hal tersebut berdampak buruk bagi perusahaan seperti terhambatnya proses produksi. Selain itu di PT. XYZ belum menerapkan konsep lean manufacturing yang dapat membantu mereka agar area kerja menjadi lebih efektif.

Berdasarkan gambaran kondisi awal perusahaan, penulis menilai bahwa kesadaran karyawan dalam memelihara area kerja pada PT. XYZ masih cukup rendah. Oleh karena itu, penulis menyarankan kepada perusahaan untuk melakukan perbaikan pada area kerja dengan cara menerapkan 5S. Metode 5S merupakan teknik paling dasar dalam menerapkan lean manufacturing yang bertujuan untuk mengeliminasi pemborosan pada area kerja sehingga tercipta lingkungan kerja yang ringkas, rapi dan bersih.

Penelitian ini terdapat kesamaan dengan penelitian Nugraha et al., (2015) pada metode yang digunakan yaitu berupa kuisioner cheklist dan pengamatan lapangan. Adapun perbedaan dari kedua penelitian yaitu pada objek penelitiannya. Objek dari penelitian ini adalah perusahaan produsen kayu lapis yang terletak di Banyumas Jawa Tengah. Sedangkan objek pada penelitian Nugraha yaitu perusahaan produsen peralatan laboratorium yang terletak di Jakarta.

\section{Landasan Teori}

\subsection{Pengertian Seiri}

Seiri atau ringkas merupakan kegiatan penyusunan berupa memilah semua peralatan, bahan, dan lain-lain di tempat kerja serta memastikan bahwa semua barang yang diperlukan disimpan pada tempat yang telah ditentukan supaya lebih efisien dengan memperhatikan frekuensi pemakaian. Untuk barang yang sudah tidak diperlukan dapat dibuang atau disimpan pada tempat yang berbeda. Hal ini dapat mengurangi ketidakefektifan dalam bekerja (Halim 2006, dikutip oleh Maitimue \& Ralahalu, 2018).

\subsection{Pengertian Seiton}

Seiton atau rapi artinya menyimpan barang di tempat yang tepat dalam tata letak yang telah ditentukan sehingga barang tersebut dapat dengan mudah ditemukan.

\subsection{Pengertian Seiso}

Seiso atau resik artinya membersihkan barang atau peralatan dari debu dan kotoran sehingga barang menjadi bersih dan tidak rusak. Dalam hal ini berarti membuang sampah, kotoran dan benda asing serta membersihakan segala sesuatu. Diutamakan sebagai pemeriksaan terhadap kebersihan dan menciptakan tempat kerja yang tidak memiliki cacat dan cela (Waluyo, 2011 dikutip oleh Maitimue \& Ralahalu, 2018).

\subsection{Pengertian Seiketsu}

Seiketsu atau rawat artinya pemeliharaan yang dilakukan secara kontinu dan berulang terhadap 3R. Tujuannya untuk menjaga supaya segala sesuatu menjadi lebih terorganisir, tertata, dan besih.

\subsection{Pengertian Shitsuke}

Shitsuke atau rajin berarti pelatihan dan penigkatan kemampuan untuk melakukan apa yang ingin kita lakukan meskipun hal tersebut sulit untuk dilakukan (Waluyo, 2011 dikutip oleh Maitimue \& Ralahalu, 2018).

\section{Metode Penelitian}

\subsection{Studi Pendahuluan}

Tahap pertama yaitu melakukan observasi lapangan yang diiringi dengan studi literatur, selanjutnya melakukan identifikasi masalah dan membuat rumusan masalah, menentukan tujuan dan batasan masalah pada penelitian ini.

\subsection{Pengumpulan Data}

\section{Data Primer}

Data primer diperoleh dengan melakukan pengamatan secara langsung atau observasi terhadap peralatan dan kondisi tempat kerja serta tahapan proses yang dilakukan. Pengamatan dilakukan di area produksi. Selain observasi peneliti juga melakukan pengumpulan data melalui wawancara dengan manager produksi dan kepala shift.

Untuk pengisian checklist peneliti meminta bantuan kepada supervisor yang mengetahui bagaimana kondisi di area produksi. Sebelum mengisi checklist auditor diberikan penjelasan terlebih dahulu mengenai proses audit dan bagaimana cara mengisi checklist. Setelah auditor diberikan penjelasan dan mengerti apa yang telah dijelaskan, kemudian auditor menjawab beberapa pertanyaan berupa checklist untuk melakukan penilaian.

\section{Data Sekunder}

Data sekunder berasal dari literatur, kepustakaan, dan penelitian terdahulu yang 
berkaitan dengan penerapan lean manufacturing dengan metode 5S.

\subsection{Pengolahan Data}

Data yang sebelumnya telah diperoleh seperti checklist audit, proses produksi, dan hasil pengamatan area kerja selanjutnya diolah dan dianalisa. Adapun pengolahan datanya yaitu:

\section{Skoring pada Kondisi Sebelum}

Perbaikan. Skoring dilakukan pada data checklist audit yang telah diperoleh. Skor total untuk kondisi sempurna adalah 4 x 38 $=152$

2. Rekapitulasi Hasil Temuan. Untuk melakukan perbandingan, maka peneliti juga mengamati secara langsung kondisi di lapangan. Dari hasil pengamatan tersebut kemudian diperoleh permasalahan sesungguhnya yang terdapat di lantai produksi. Kemudian dilakukan analisa sebagai hasil temuan

3. Evaluasi Sebelum Perbaikan. Pada tahap ini dilakukan penilaian $5 \mathrm{~S}$ menggunakan checklist evaluasi yang telah disusun sebelumnya.

\subsection{Analisa dan Pembahasan}

Tahap selanjutnya adalah melakukan analisa yang meliputi penentuan kebutuhan, usulan perbaikan, implementasi usulan perbaikan, dan evaluasi setelah perbaikan.

\subsection{Kesimpulan dan Saran}

Tahap ini adalah membuat kesimpulan dan saran yang diberikan berdasar hasil penelitian.

\section{Hasil Dan Pembahasan}

\subsection{Skoring pada Kondisi Sebelum Perbaikan}

Dalam pengisian data checklist penulis meminta bantuan seorang auditor yang mengerti kondisi pada lantai produksi. Dalam penelitian ini penulis memilih supervisor sebagai auditor. Supervisor adalah anggota manajemen yang bekerja pada suatu tingkat organisasi dan bertugas untuk melakukan pengawasan atas tugastugas yang diserahkan kepada kelompokkelompok kecil dengan tujuan untuk menjamin hasil kerja yang memuaskan (Widaningsih \& Chaniago,2019). Supervisor menangani dua hal yaitu tugas dari managernya dan sekaligus membantu bawahannya di lapangan. Oleh karena itu supervisor dianggap orang yang paling tepat dijadikan auditor dalam penelitian ini.

Pembuatan tabel merujuk pada penelitian Nugraha et al., (2015) kemudian disesuaikan dengan kondisi yang ada pada perusahaan yang penulis teliti. Kriteria 0 pada tabel menunjukkan nilai sangat tidak setuju, kriteria 1 menunjukkan nilai tidak setuju, kriteria 2 menunjukkan nilai sedang, kriteria 3 menunjukkan nilai setuju, kriteria 4 menunjukkan nilai sangat setuju.

Tabel 1 Hasil Checklist Audit pada Area Packing

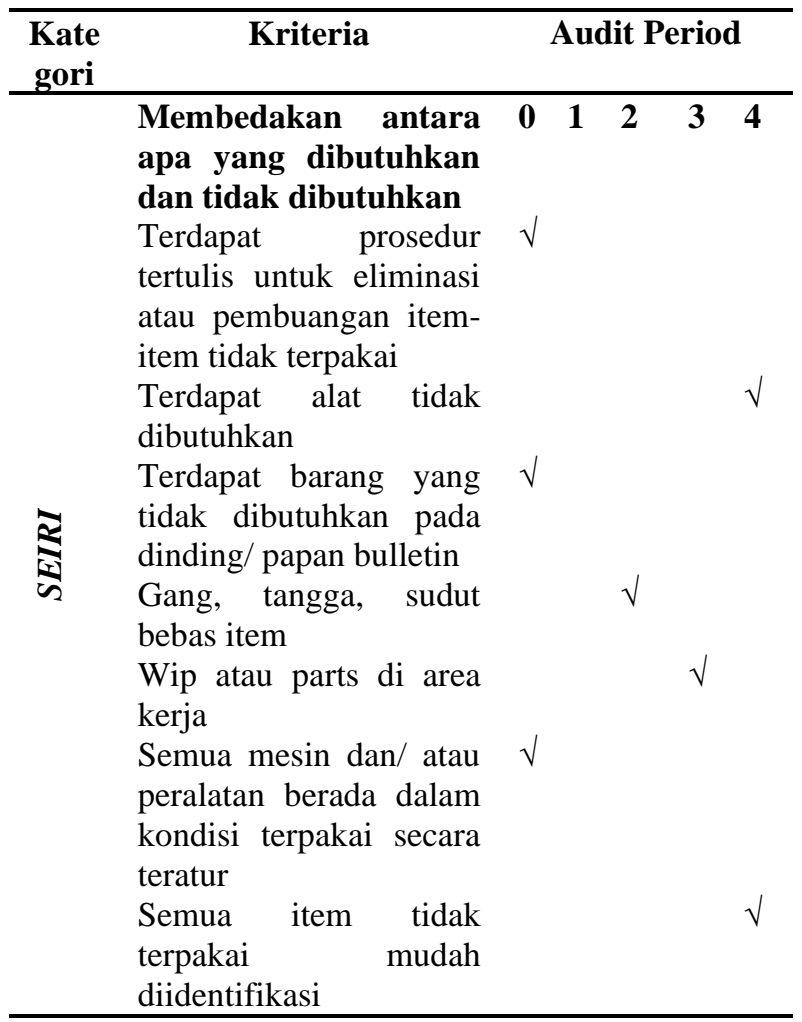

Kategori yang lain (Seiton, Seiso, Seiketsu, Shitsuke) dilakukan dengan cara yang sama pada area kerja yang sama dengan jumlah total pertanyaan 38 menghasilkan nilai 44 .

Untuk area kerja lain dengan cara yang sama diperoleh nilai:

1. Rotary $=31$

2. Pressdryer $=20$

3. Repair $=25$

4. Assembling $=27$

\subsection{Rekapitulasi Hasil Temuan}

Berdasarkan hasil checklist audit yang telah dilakukan oleh auditor kemudian penulis melakukan pengamatan langsung di lapangan untuk mengetahui dan mencatat permasalahan permasalahan yang sebenarnya terjadi 
Tabel 2 Hasil Rekapitulasi Temuan di Lapangan pada Area Packing

\begin{tabular}{|c|c|c|}
\hline \multirow[t]{2}{*}{ No } & \multicolumn{2}{|c|}{ SEIRI } \\
\hline & $\begin{array}{c}\text { Membedakan } \\
\text { antara apa yang } \\
\text { dibutuhkan dan } \\
\text { tidak dibutuhkan }\end{array}$ & Catatan Temuan \\
\hline 1 & $\begin{array}{lr}\text { Terdapat prosedur } \\
\text { tertulis } \\
\text { eliminasi untuk } \\
\text { pembuangan item- } \\
\text { item tidak terpakai }\end{array}$ & $\begin{array}{l}\text { Tidak terdapat } \\
\text { prosedur tertulis } \\
\text { untuk eliminasi }\end{array}$ \\
\hline 2 & $\begin{array}{l}\text { Terdapat alat tidak } \\
\text { dibutuhkan }\end{array}$ & $\begin{array}{lr}\text { Alat } & \text { tidak } \\
\text { dibutuhkan } & \text { seperti } \\
\text { amplas, makanan } \\
\text { dan } & \text { minuman } \\
\text { karyawan } & \end{array}$ \\
\hline 3 & $\begin{array}{l}\text { Terdapat barang yang } \\
\text { tidak dibutuhkan pada } \\
\text { dinding/ papan buletin }\end{array}$ & $\begin{array}{lr}\text { Tidak } & \text { terdapat } \\
\text { barang } & \text { tidak } \\
\text { dibutuhkan } & \text { pada } \\
\text { dinding } & \end{array}$ \\
\hline 4 & $\begin{array}{l}\text { Gang, tangga, sudut } \\
\text { bebas item }\end{array}$ & $\begin{array}{l}\text { Sudut sebagai } \\
\text { tempat } \\
\text { penyimpanan } \\
\text { barang }\end{array}$ \\
\hline 5 & $\begin{array}{l}\text { Wip atau parts di area } \\
\text { kerja }\end{array}$ & $\begin{array}{l}\text { Terdapat WIP di } \\
\text { area kerja }\end{array}$ \\
\hline 6 & $\begin{array}{l}\text { Semua mesin dan/ } \\
\text { atau peralatan berada } \\
\text { dalam kondisi } \\
\text { terpakai secara teratur }\end{array}$ & $\begin{array}{l}\text { Amplas dan cutter } \\
\text { terpakai } \\
\text { teratur }\end{array}$ \\
\hline 7 & $\begin{array}{lr}\text { Semua item tidak } \\
\text { terpakai } \\
\text { diidentifikasi }\end{array}$ & $\begin{array}{l}\text { Tidak ada } \\
\text { tersembunyi }\end{array}$ \\
\hline
\end{tabular}

Kategori yang lain (Seiton, Seiso, Seiketsu, Shitsuke) dilakukan dengan cara yang sama pada area kerja yang sama.

Untuk area kerja lain dilakukan dengan cara yang sama untuk mengetahui permasalahan yang sebenarnya terjadi pada tiap area kerja.

\subsection{Penilaian Kondisi Sebelum Perbaikan}

Tabel 3 Hasil Penilaian Kondisi Sebelum Perbaikan

\begin{tabular}{lllllll}
\hline $\mathbf{N}$ & \multicolumn{1}{c}{ Pernyataan } & \multicolumn{4}{c}{ Skor } \\
\cline { 3 - 6 } $\mathbf{0}$ & & $\mathbf{1}$ & $\mathbf{2}$ & $\mathbf{3}$ & $\mathbf{4}$ & $\mathbf{5}$ \\
\hline $\mathbf{1}$ & & Setiap karyawan telah & & $\sqrt{ }$ & & \\
& memberikan & & & & \\
& kontribusi terhadap & & & & \\
& proses pemilahan & & & & \\
& barang untuk & & & & \\
& menyingkirkan item & & & & \\
& item yang tidak & & & & \\
\hline
\end{tabular}

diperlukan di area kerja

2 Setiap karyawan telah menjalankan

prosedur untuk menerapkan 3s

3 Semua mesin dan peralatan telah disimpan pada tempat yang ditentukan. Manajemen menunjuk salah seorang karyawan untuk bertanggung jawab memelihara mesin, peralatan, dan tempat kerja.

4 Seluruh mesin, peralatan, dan area kerja tampak bersih dan terpelihara dengan baik

5 Terdapat 5s visual board atau poster sebagai alat manajemen visual yang memungkinkan untuk dilihat oleh setiap karyawan sehingga mereka mengetahui dan mengerti menegenai standar stand 5s yang ditentukan

6 Terdapat prosedur dan intruksi kerja mengenai $5 \mathrm{~s}$ yang diperbaharui secara berkala

7 Seluruh karyawan telah memperoleh pelatihan mengenai 5s agar memahami tentang prinsip prinsip 5s

8 Terdapat pemberian penghargaan yang berlaku secara formal untuk memotivasi karyawan dalam menerapkan 5s

9 Terdapat sistem penilaian $5 \mathrm{~s}$ berupa audit secara berkala, skor audit dikomunikasikan secara visual melalui 5s visual board. 


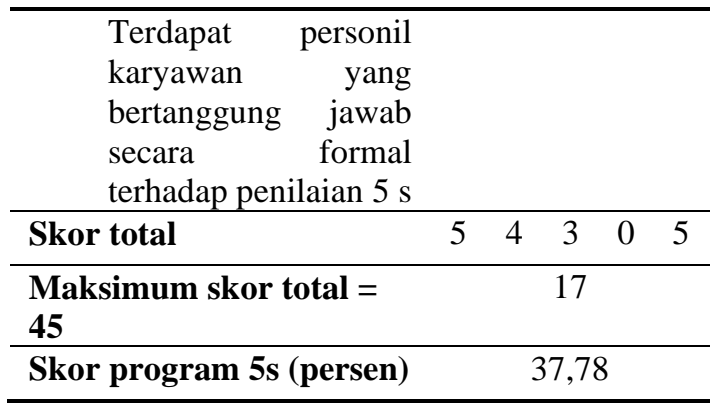

Berdasarkan hasil penilaian kondisi $5 \mathrm{~s}$ pada tabel diatas diperoleh skor sebesar 37,78\%. Menurut Nugraha et al., (2015) skor tersebut menunjukkan bahwa kondisi perusahaan sebelum perbaikan adalah buruk. Oleh karena itu perusahaan memerlukan perbaikan.

\subsection{Penentuan Kebutuhan}

Berdasarkan pada masalah yang terjadi kemudian dirancang penentuan kebutuhan sesuai dengan hasil temuan. Kondisi perusahaan sesuai hasil temuan tersebut yang kemudian dijadikan dasar dalam merancang perbaikan. Berikut ini disajikan tabel penentuan kebutuhan pada lantai produksi.

Tabel 4 Penentuan Kebutuhan

\begin{tabular}{|c|c|c|}
\hline No & Temuan Masalah & Kebutuhan \\
\hline 1 & $\begin{array}{l}\text { Tidak terdapat } \\
\text { prosedur tertulis untuk } \\
\text { eliminasi }\end{array}$ & Prosedur tertulis \\
\hline 2 & $\begin{array}{l}\text { Tidak terdapat label } \\
\text { pada area kerja }\end{array}$ & Label \\
\hline 3 & $\begin{array}{l}\text { Belum ada } \\
\text { pembersihan secara } \\
\text { teratur }\end{array}$ & $\begin{array}{l}\text { Jadwal } \\
\text { pembersihan }\end{array}$ \\
\hline 4 & $\begin{array}{l}\text { Karyawan belum } \\
\text { memahami 5s }\end{array}$ & $\begin{array}{l}\text { Sosialisasi dan } \\
\text { training } \\
\text { mengenai 5s }\end{array}$ \\
\hline 5 & $\begin{array}{l}\text { Belum ada prosedur } \\
\text { dan standar } 5 \mathrm{~s}\end{array}$ & $\begin{array}{l}\text { Prosedur tertulis } \\
\text { dan standar } 5 \mathrm{~s}\end{array}$ \\
\hline 6 & $\begin{array}{l}\text { Belum ada audit } \\
\text { mengenai } 5 \mathrm{~s}\end{array}$ & Audit \\
\hline 7 & $\begin{array}{l}\text { Belum terdapat } \\
\text { manajemen visual, } \\
\text { sistem dan prosedur } \\
\text { standar mengenai 5s }\end{array}$ & Poster 5s \\
\hline 8 & $\begin{array}{l}\text { Banyak sampah yang } \\
\text { berceceran }\end{array}$ & Tempat sampah \\
\hline 9 & $\begin{array}{l}\text { Permukaan kerja kotor } \\
\text { dan sulit dibersihkan }\end{array}$ & $\begin{array}{l}\text { Penggantian } \\
\text { permukaan } \\
\text { kerja }\end{array}$ \\
\hline 10 & $\begin{array}{l}\text { Setiap orang tidak } \\
\text { terlibat dalam kegiatan } \\
5 \mathrm{~s}\end{array}$ & $\begin{array}{l}\text { Motivasi } \\
\text { dengan } \\
\text { pemberian } \\
\text { reward }\end{array}$ \\
\hline
\end{tabular}

\subsection{Usulan Perbaikan}

Usulan perbaikan dirancang berdasarkan kebutuhan yang telah diidentifikasi. Implementasi 5 s diperlukan pada masing - masing area kerja sesuai dengan kebutuhan - kebutuhan yang telah ditentukan. Usulan perbaikan yang telah dirancang adalah sebagai berikut.

1. Membuat prosedur tertulis mengenai eliminasi barang tidak terpakai dan daur ulang

2. Pemberian label yang menunjukkan area produksi, penyimpanan, dan part serta mesin.

3. Membuat jadwal pembersihan secara teratur bagi setiap karyawan di area produksinya masing-masing

4. Memberikan sosialisasi dan pelatihan mengenai 5s kepada karyawan

5. Membuat prosedur tertulis penerapan $5 \mathrm{~s}$ dan standar tertulis mengenai $5 \mathrm{~s}$

6. Membuat sistem audit secara berkala

7. Membuat poster dan alat manajemen visual lainnya tentang $5 \mathrm{~s}$

8. Menyediakan tempat sampah pada setiap area kerja

9. Mengganti permukaan kerja dengan lantai

10. Memberikan penghargaan kepada karyawan yang menerapkan $5 \mathrm{~s}$

\subsection{Implementasi Usulan Perbaikan}

1. Pemberian Label pada Area Packing Label penyimpanan
Produk

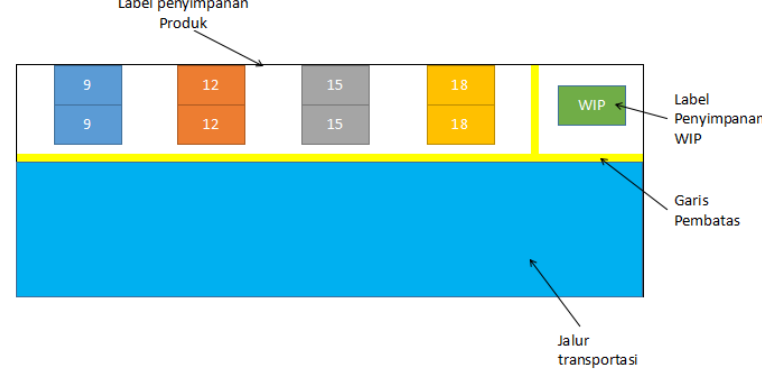

Gambar 1 Visualisasi Pemberian Label pada Area Packing

Sumber: Pengolahan data

Gambar 1 menunjukkan penggambaran area packing setelah perbaikan. Sesuai dengan usulan perbaikan yaitu dengan menambahkan label pada area kerja dan area part/ barang. Label dituliskan diatas lantai supaya operator forklift dapat dengan mudah melihat area-area yang ada sehingga penataan barang menjadi lebih rapi. Selain itu juga diberikan garis pembatas agar barang tersusun rapi secara teratur sehingga tidak menghalangi jalur transportasi. Jalur transportasi ini digunakan oleh forklift dan container yang akan mengangkut barang. 
2. Pembuatan Poster

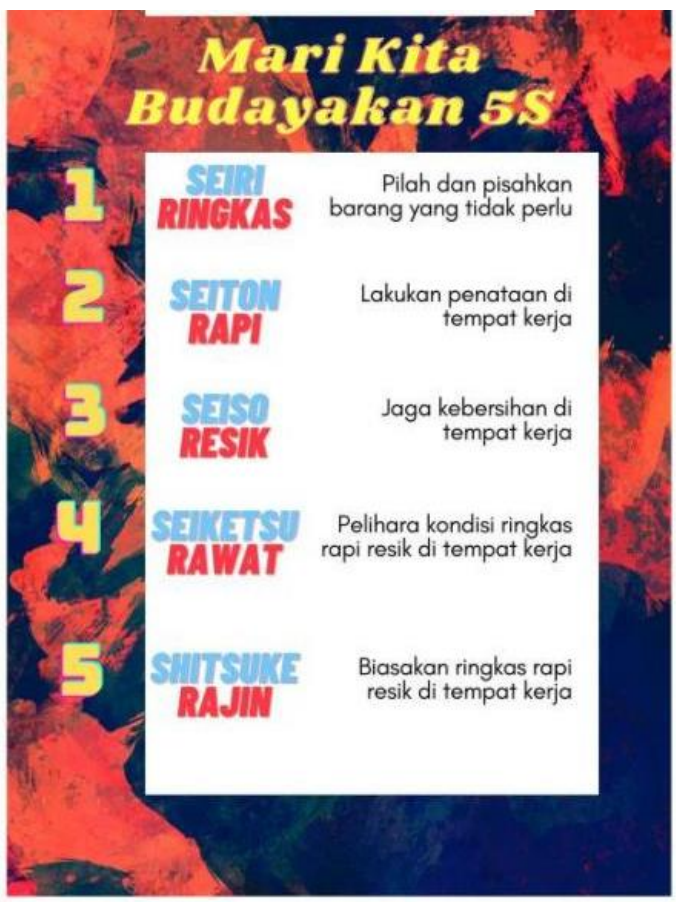

Gambar 2 Poster 5S

Sumber: Pengolahan data

Gambar 2 merupakan poster yang menjelaskan mengenai kegiatan 5s. Poster berguna untuk memberi informasi agar penerapan $5 \mathrm{~s}$ berjalan dengan lebih baik. Pembuatan poster diharapkan dapat memotivasi karyawan untuk senantiasa menerapkan budaya kerja $5 \mathrm{~s}$ dalam kesehariannya (Wiratmani, 2010).

3. Perancangan Prosedur Tertulis Penerapan 5S

Kegiatan seiri yang dirancang bertujuan untuk menghilangkan barang-barang yang tidak diperlukan sehingga area kerja menjadi lebih ringkas.

Tabel 5 Prosedur Tertulis Seiri

\begin{tabular}{cl}
\hline \multicolumn{1}{c}{ SEIRI } \\
\hline No & \multicolumn{1}{c}{ Langkah yang Dilakukan } \\
\hline $\mathbf{1}$ & $\begin{array}{l}\text { Cek semua barang yang ada di setiap area } \\
\text { kerja }\end{array}$ \\
$\mathbf{2}$ & $\begin{array}{l}\text { Bedakan kategori barang menjadi barang } \\
\text { diperlukan dan barang tidak perlukan }\end{array}$ \\
$\mathbf{3}$ & $\begin{array}{l}\text { Tandai barang tidak diperlukan dengan } \\
\text { label warna merah (red tag) kemudian } \\
\text { pindahkan ke tempat pembuangan } \\
\text { sementara (tps) }\end{array}$ \\
\hline
\end{tabular}

4 Untuk barang yang tidak diperlukan namun tidak dapat dipindahkan tandai dengan label warna kuning (yellow tag)

5 Siapkan suatu tempat pembuangan untuk menyimpan/membuang/memusnahkan barang -barang yang tidak diperlukan

6 Pindahkan semua barang yang diberi tanda label merah ke tempat pembuangan untuk dimusnahkan
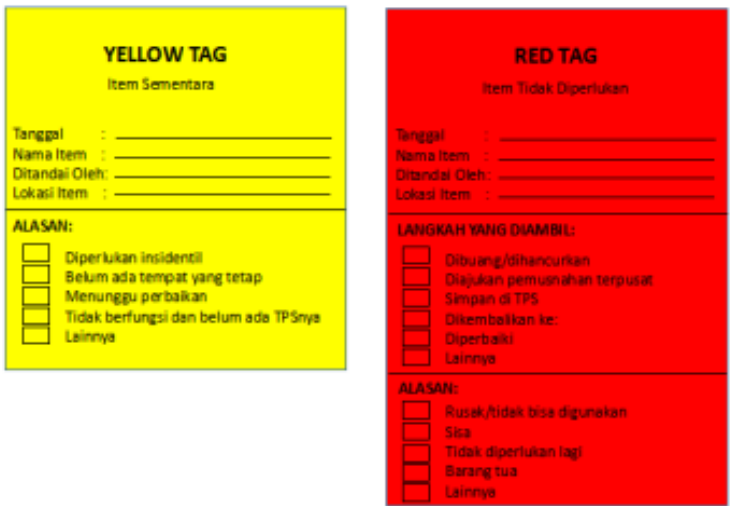

Gambar 3 Yellow Tag dan Red tag untuk Memilah Barang

Gambar diatas merupakan kartu identifikasi untuk barang atau item yang akan disisihkan apakah masih diperlukan atau tidak.

Kegiatan seiton yang dirancang bertujuan untuk memastikan bahwa semua barang dan peralatan yang ada di area kerja diletakkan sesuai dengan posisi yang ditetapkan sehingga siap digunakan setiap saat ketika diperlukan.

Tabel 6 Prosedur Tertulis Seiton

\begin{tabular}{cl}
\hline \multicolumn{2}{c}{ SEITON } \\
\hline No & \multicolumn{1}{c}{ Langkah yang Dilakukan } \\
\hline $\mathbf{1}$ & $\begin{array}{l}\text { Rancang metode untuk menempatkan } \\
\text { barang sehingga mudah ditemukan ketika } \\
\text { diperlukan }\end{array}$ \\
$\mathbf{2}$ & $\begin{array}{l}\text { Tempatkan semua barang yang diperlukan } \\
\text { pada posisi yang telah ditentukan }\end{array}$
\end{tabular}

3 Berikan label untuk memudahkan identifikasi barang sehingga barang dapat dengan mudah dikembalikan ke tempat semula setelah digunakan

Kegiatan seiso yang dirancang bertujuan untuk memastikan kebersihan barang dan peralatan agar selalu dalam kondisi yang baik. 
Tabel 7 Prosedur Tertulis Seiso

\begin{tabular}{clc}
\hline \multicolumn{4}{c}{ SEISO } \\
\hline No & \multicolumn{3}{c}{ Langkah yang Dilakukan } \\
\hline $\mathbf{1}$ & $\begin{array}{l}\text { Temukan sumber kotoran beserta penyebab } \\
\text { timbulnya kotoran }\end{array}$ \\
$\mathbf{2}$ & $\begin{array}{l}\text { Tetapkan tindakan } \\
\text { diperlukan tindakan yang }\end{array}$ \\
& mengurangi timbulnya kotoran & \\
\hline
\end{tabular}

Kegiatan seiketsu yang dirancang yaitu dengan membuat kegiatan seiri, seiton, dan seiso menjadi kegiatan standar. Tujuannya agar pekerjaan 3s sebelumnya menjadi kegiatan yang selalu dilakukan secara teratur.

Tabel 8 Prosedur Tertulis Seiketsu

\begin{tabular}{cl}
\hline \multicolumn{1}{c}{ SEIKETSU } \\
\hline No & \multicolumn{1}{c}{ Langkah yang Dilakukan } \\
\hline $\mathbf{1}$ & $\begin{array}{l}\text { Tetapkan standar penataan barang yang } \\
\text { diperlukan, penempatan posisi barang, serta } \\
\text { kebersihannya } \\
\mathbf{2}\end{array}$ \\
$\begin{array}{l}\text { Sosialisasikan standar ke seluruh karyawan } \\
\text { yang bekerja }\end{array}$ \\
\hline
\end{tabular}

Kegiatan shitsuke yang dirancang bertujuan untuk membiasakan kegiatan $5 \mathrm{~s}$ agar berjalan terus menerus secara berkesinambungan serta penyadaran diri kepada seluruh karyawan akan pentingnya penerapan $5 \mathrm{~s}$.

Tabel 9 Prosedur Tertulis Shitsuke

\begin{tabular}{cl}
\hline \multicolumn{1}{c}{ SHITSUKE } \\
\hline No & \multicolumn{1}{c}{ Langkah yang Dilakukan } \\
\hline $\mathbf{1}$ & $\begin{array}{l}\text { Pastikan kondisi area kerja selalu sesuai } \\
\text { dengan standar yang telah ditetapkan }\end{array}$ \\
$\mathbf{2}$ & $\begin{array}{l}\text { Lakukan pengecekan di setiap area kerja } \\
\text { setiap saat }\end{array}$ \\
$\mathbf{3}$ & Koreksi apabila terjadi pelanggaran \\
$\mathbf{4}$ & Lakukan peningkatan secara terus menerus \\
\hline
\end{tabular}

\subsection{Evaluasi Setelah Perbaikan}

Tabel 10 Checklist Evaluasi Setelah Perbaikan

\begin{tabular}{lllllll}
\hline No & \multicolumn{2}{c}{ Pernyataan } & \multicolumn{4}{c}{ Skor } \\
\cline { 3 - 6 } & & & & & \\
\cline { 3 - 6 } & & $\mathbf{2}$ & $\mathbf{3}$ & $\mathbf{4}$ & $\mathbf{5}$ \\
\hline $\mathbf{1}$ & $\begin{array}{l}\text { Setiap karyawan telah } \\
\text { memberikan kontribusi } \\
\text { terhadap }\end{array}$ & & & & & \\
& pemilahan barang untuk & & & & & \\
\hline
\end{tabular}

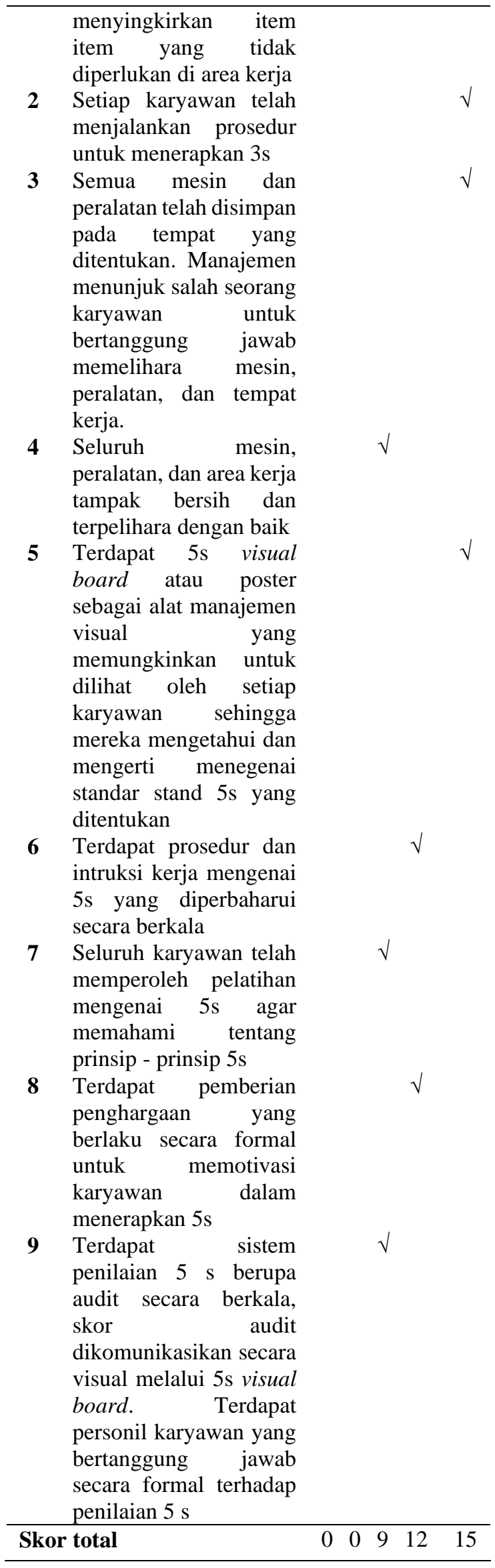




\begin{tabular}{ll}
\hline Maksimum skor total $=\mathbf{4 5}$ & 36 \\
\hline Skor program 5s (persen) & 80 \\
\hline
\end{tabular}

Berdasarkan tabel evaluasi diatas diperoleh skor penilaian 5s sebesar $80 \%$ dengan kategori baik. Artinya apabila perusahaan benar-benar mengimplementasikan usulan yang diberikan maka akan meningkatkan skor penilaian $5 \mathrm{~s}$ secara signifikan.

\section{Kesimpulan dan Saran}

\subsection{Kesimpulan}

Berdasarkan hasil penelitian yang telah dilakukan, maka diperoleh kesimpulan sebagai berikut.

1. Permasalahan yang terdapat di lantai produksi PT XYZ antara lain: tidak terdapat prosedur tertulis untuk eliminasi, tidak terdapat label pada area kerja, belum ada pembersihan secara teratur, karyawan belum memahami $5 \mathrm{~s}$, belum ada prosedur dan standar $5 \mathrm{~s}$, belum ada audit mengenai $5 \mathrm{~s}$, belum terdapat manajemen visual sistem dan prosedur standar mengenai 5s, banyak sampah yang berceceran, permukaan kerja kotor dan sulit dibersihkan, setiap orang tidak terlibat dalam kegiatan $5 \mathrm{~s}$

2. Skor penilaian $5 \mathrm{~s}$ sebelum perbaikan sebesar $37,78 \%$ dengan kategori buruk. Setelah merencanakan implementasi perbaikan skor naik menjadi $80 \%$ dengan kategori baik.

\subsection{Saran}

Berdasarkan hasil penelitian yang telah dilakukan, maka saran yang dapat diberikan bagi perusahaan dan bagi penelitian selanjutnya adalah sebagai berikut.

1. Sebaiknya perusahaan mempertimbangkan penerapan usulan $5 \mathrm{~s}$ ini guna membentuk area kerja yang efektif dan nyaman.

2. Penelitian selanjutnya sebaiknya menambahkan implementasi perbaikan secara aktual di perusahaan.

3. Metode 5 s merupakan metode awal dalam implementasi lean manufacturing, maka pada penelitian selanjutnya terkait penerapan lean dapat menambahkan metode lainnya.

\section{Daftar Pustaka}

Aisyah, S. (2020). Mengurangi Pemborosan Menggunakan Metode Value Stream Mapping Pada PT Y Indonesia. 02(02), 5659.
Maitimue, N. E., \& Ralahalu, H. Y. P. (2018). Perancangan Penerapan Metode 5S Di Pabrik Sarinda Bakery. Arika, 12(1), 1-10. https://doi.org/10.30598/arika.2018.12.1.1

Nugraha, A. S., Desrianty, A., \& Irianti, L. (2015). Usulan Perbaikan Berdasarkan Metode 5S (Seiri, Seiton, Seiso, Seiketsu, Shitsuke) Untuk Area Kerja Lantai Produksi Di PT.X. Jurnal Teknik Industri, 3(4), 1-11.

S, Sylvia. (2020). Implementasi Metode 5S Sebagai Usulan Perbaikan dan Pengembangan Manajemen Operasional dan Area Kerja di. 1(3).

Silalahi, S. A. F. (2014). Kondisi Industri Manufaktur Indonesia Dalam Menghadapi Globalisasi. Jurnal Ekonomi Dan Kebijakan Publik, 5(1), 1-13.

Widaningsih, U., \& Chaniago, H. (2019). Perusahaan ( the Effect of Role of a Manager and Supervisor for Companies ). 1-13.

Wiratmani, E. (2010). IMPLEMENTASI METODE 5S PADA DIVISI GUDANG BARANG JADI ( Studi Kasus Pada PT . X ). Jurnal Teknik Industri, 3(3), 1-19. https://journal.lppmunindra.ac.id/index.php/ Faktor_Exacta/article/download/26/25 